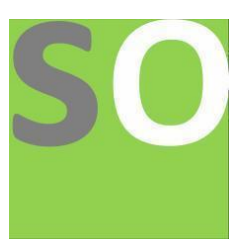

Article title: After one year of COVID-19 Pandemic and Hundreds of Suggested Drugs, Will Cathepsin L Inhibitors be the Solution?

Authors: Amr Kamel Khalil Ahmed[1]

Affiliations: Tuberculosis program, Public Health department, First health Cluster, Ministry of Health, Saudia Arabia[1]

Orcid ids: 0000-0003-3477-236X[1]

Contact e-mail: drmedahmed@gmail.com

License information: This work has been published open access under Creative Commons Attribution License http://creativecommons.org/licenses/by/4.0/, which permits unrestricted use, distribution, and reproduction in any medium, provided the original work is properly cited. Conditions, terms of use and publishing policy can be found at https://www.scienceopen.com/.

Preprint statement: This article is a preprint and has not been peer-reviewed, under consideration and submitted to ScienceOpen Preprints for open peer review.

Links to data: https://zenodo.org/record/4682214\#.YIFPXuszbct

Funder: No

DOI: 10.14293/S2199-1006.1.SOR-.PPAJTMC.v1

Preprint first posted online: 22 April 2021

Keywords: COVID-19, Lactoferrin , Bromelain, Quercetin, Zinc, Metformin, Docking, Viral Fusion, SARS-CoV-2, Cathepsin $\mathrm{L}$ 


\title{
After one year of COVID-19 Pandemic and Hundreds of Suggested Drugs, Will Cathepsin L Inhibitors be the Solution?
}

\author{
Amr Ahmed ${ }^{1} \odot$, Mohammad Nezami ${ }^{2}$, Abdullah Alkattan $^{3,4}$, Ahmed Mohamed $^{5}$, \\ Omar Alshazly ${ }^{6}$, Simona Ibrahim ${ }^{7}$
}

${ }^{1}$ Department of Public Health, Tuberculosis Program, First Health Cluster, Riyadh, Saudi Arabia.

${ }^{2}$ President and CEO of Sahel Oncology LLC, Orange Coast Medical Center of Hope Inc. 496 Old Newport Blvd. \#7 Newport Beach, CA 92612, USA.

${ }^{3}$ Deaprtment of Research and Development, General Directorate of Medical Consultations, Ministry of Health, Riyadh, Saudi Arabia.

${ }^{4}$ Department of Biomedical Sciences, College of Veterinary medicine, King Faisal University, Al-Hofuf, Saudi Arabia.

${ }^{5}$ Faculty of Dentistry, The British University in Egypt, Cairo, Egypt.

${ }^{6}$ Department of Pharmacology, Faculty of Pharmacy, Sohag University, Sohag, Egypt.

${ }^{7}$ Department of Pharmaceutical Chemistry, Faculty of Pharmacy, The British University in Egypt, Cairo, Egypt.

Correspondence to:

Amr Ahmed - email: drmedahmed@gmail.com

Mohammad Nezami - email: amnezami@saheloncology.com

Abdullah Alkattan - email: abdullahalkattan@gmail.com

Ahmed Mohamed - email: ahmed153080@bue.edu.eg

Simona Ibrahim - email: simona.salaam@bue.edu.eg 


\begin{abstract}
Cysteine cathepsins are defined as lysosomal enzymes which are member of the papain family. Cysteine cathepsins (Cts) prevalently exist in whole organisms varying from prokaryotes to mammals and possess in their active site greatly conserved residue of cysteine. Cts are engaged in the digestion of cellular protein, activation of zymogen, and remodeling of extracellular matrix (ECM). Host cells are entered by SARS-CoV2 via endocytosis. Cathepsin L and phosphatidylinositol 3-phosphate 5-kinase are crucial in terms of the endocytosis by cleaving the spike protein, which permits viral membrane fusion with endosomal membrane, and succeeded by the releasing of viral genome to the host cell. Thereby, inhibition of cathepsin L may be advantageous in terms of decreasing infection caused by SARS-CoV-2. Coordinate inhibition of multiple Cts and lysosomal function by different drugs and biological agents might be of value for some purposes such as parasite or viral infections and anti-neoplastic applications. It has been found that $\mathrm{Zn}^{2+}$ deficiency or dysregulation leads to an exaggerated activity of Cysteine cathepsin increasing the autoimmune/inflammatory response. At this purpose $\mathrm{Zn}^{2+}$ metal can be safely combined with a drug that increases the anti-proteolytic effect of endogenous $\mathrm{Zn}^{2+}$ lowering the excessive activity of some CysCts. Biguanide derivatives complex with $\mathrm{Zn}^{2+}$ have been found to be promising inhibitors of CysCts protease reactions. Molecular docking studies of Cathepsin $\mathrm{L}$ Inhibited by Metformin-Zn+2 complex have been performed showing two strong key interactions ( Cys-25\&His-163) and an extra H-bond with Asp-163 compared to the cocrystallized $\mathrm{Zn}^{+2}$ (PDB ID 4axl).
\end{abstract}

\title{
Keywords
}

COVID-19, Cathepsin L, SARS-CoV-2, Viral Fusion, Docking, Metformin, Zinc

,Quercetin , Bromelain ,Lactoferrin 


\section{1) Introduction}

Cysteine cathepsins which are described as lysosomal enzymes are a member of the papain family. In a broad range of tumors the expression of cysteine cathepsins is dysregulated. Moreover, ample data asserted their engagement in the progression of cancer, metastasis, angiogenesis and drug resistance. In addition to that, they importantly contribute to some viral infections [1,2]. In accordance to the active site of cathepsins which are lysosomal proteases, their subclassification can include aspartate, serine cathepsins and cysteine [1].

Cathepsins (Cts) are prevantely exist in whole organisms varying from prokaryotes to mammals and possess in their active site a greatly conserved cysteine residue. In term of the proteins degradation, they are fundamental in which they are incorporated in the lysosomes via phagocytosis, auto-phagocytosis and endocytosis[3]. In addition to that, their engagement presents in the digestion of cellular protein, activation of zymogen, and remodeling of extracellular matrix (ECM) [4, 5]. In accordance with physiologicalrelated conditions, Cts are essential in term of tissue homeostasis maintenance, also their engagement presents in various processes namely differentiation, development, apoptosis and immune response[6]. Changes in activity, localization and expression of Cts have been linked to multiple pathological-related disorders, comprising progression of cancer [7, 8], Additionally ectopic expression of Cts is commonly correlated with poor prognosis[9].

The Cts family proteases comprises the subtypes B, C, F, H, K, L, O, S, V, W, and $\mathrm{X}[10]$ that mature in the lysosomes acidic environment. Additionally to the status of both redox and $\mathrm{pH}$ of the vicinity microenvironment, the biological inhibitors and activators are controlling their proteolytic activity, including growth factors, cytokines, endogenous inhibitors and collagen peptides $[11,12]$. In accordance to the Cts family proteases proteolytic activity, further classification can be performed into exopeptidases (Cts C and X) or endopeptidases (F, O, S, K, V, L, and W), along with $\mathrm{Cts} \mathrm{H}$ and $\mathrm{B}$ which possess both exopeptidase and endo activities[13]. The $\mathrm{Cts}$ specific contribution regarding phenomena of chemoresistance occurrence is presently at issue. CtsB and L overexpression was linked to the inactivation of drug increase and, most importantly, with trafficking of lysosome increase to the membrane of plasma and lysosomalcargo secretion [14], and consequently, knock-down of CTSL in cancer of ovarian cells SCOV3 led to apoptosis increase with induction of paclitaxel which is the most prevalent drug in ovarian cancer treatment [15], Moreover, Cts L contributed to the inhibition of the process of cell senescence in various lines of tumor cell, contributing a further protease-mediated drug target eradication mechanism (confining a drug within lysosomes) and resistance of drug [16-18]. Within this framework, Cts L inhibition led to increase of accumulation of Doxorubicin cell and a further convenient nuclear distribution of drug in the cells in spite of the expression of P-gp [18]. The inhibition of CstL is stabilized and improved the availableness of nuclear and cytoplasmic targets of drug including the receptor of estrogen- $\alpha$, Bcr-Abl, topoisomerase-II $\alpha$, androgen receptor I and the histone deacetylase 1, leading to cellular 
response increase for various therapeutics drugs ( tamoxifen, doxorubicin, trichostatin A, flutamide, and imatinib) [18]. Much work continues to exist to be performed in the utilize of Cts inhibitors in opposition to neoplasia but also cysteinyl cathepsins are produced by viruses, bacteria, parasites and fungi with a diversity of functions, thus making suggestion of another probable utilize of inhibitors[19]. Host cell CysCts are also engaged in some important viruses infectivity, e.g., Ebola [20], SARS-CoV-2 as well (principally) is currently renowned that it accesses cells via endocytosis. Phosphatidylinositol 3-phosphate 5-kinase and cathepsin $\mathrm{L}$ are crucial for the endocytosis[21]. In resemblance to SARS-CoV, succeeding SARS-CoV-2 endocytosis, is cathepsin $\mathrm{L}$ cleaves protein $\mathrm{S}$, that permits viral membrane fusion along with the endosomal membrane, and, consequently, release of viral genome into the host cell occurs. Thus, inhibition of cathepsin L may be advantageous in decreasing SARS-CoV [22] and SARS-CoV-2 infection [21].

Cysteinyl cathepsin inhibitors can possess "poly-therapeutic" actions in opposition to low-level inflammation in combination with autoimmunity. The low-level inflammation and autoimmunity combination has a contribution to various age-linked diseases of unrelated reasons. Several Cts in diverse types of cell underlie multiple processes necessary for inflammation and autoimmunity, e.g. , response of cytokine, processing of lysosomal antigen, extracellular degradation, serine protease zymogens activation, etc. Amid several fine studies, a few milestones emerge for their perspicuity on Cts in inflammation requirements[23] and autoimmunity[24]. Coordinate multiple Cts and lysosomal function inhibition by different drugs and biological agents as $\mathrm{Zn}^{2+}$, Biguanides and Lactoferrin...etc might be of value for some purposes such as parasite ot viral infections, and Anti-neoplastic implementations[25].
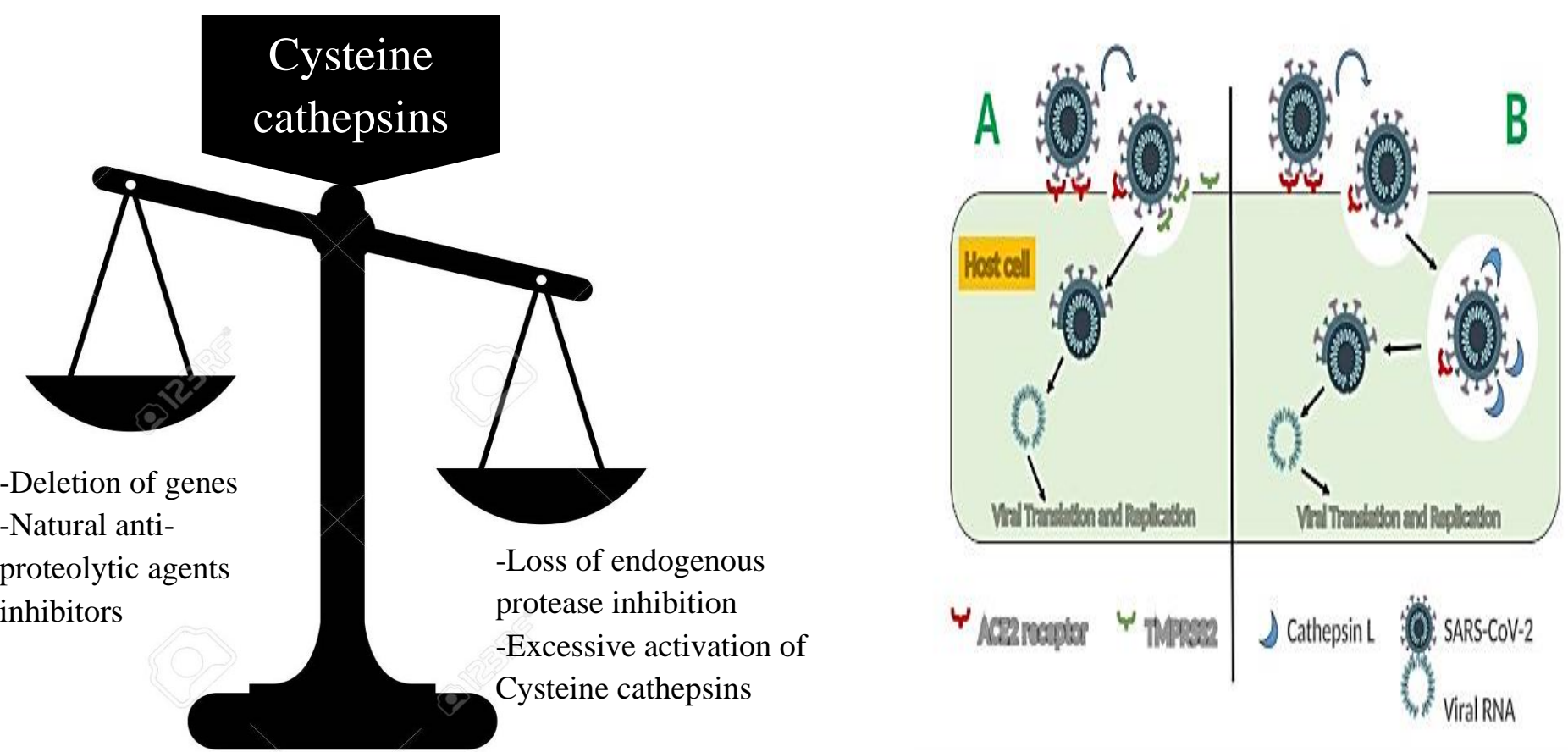

Fig. 1 Equilibrium between activators of cysteine vs anti-proteolytic agents inhibitors and its impact on the pathogenic process [116] 
Fig. 2

\section{2) Cysteinyl cathepsin $L$ inhibitors:}

1) Zinc: $\left(\mathrm{Zn}^{2+}\right)$ was figured out to be a specifically strong in term of multiple caspases inhibition[26]. Consequently, it was figured that multiple caspases inhibition is conducted by mediation of $\mathrm{Zn}^{2+}$-binding allosteric exosites which are distant from their catalytic mechanisms[27]. Also, specific viral proteases have $\mathrm{Zn}^{2+}$-binding exosites[28]. Calpain (a cysteine protease) undergoes inhibition by $\mathrm{Zn}^{2+}$ and activation by deficiency of $\mathrm{Zn}^{2+}$ [29]. It is renowned that the $\mathrm{Zn}^{2+}$ interacts with the $\mathrm{E}-\mathrm{F}$ hand structure which presents in certain papain-like viral proteases and calpains. Nonwithstanding that the $20 \mathrm{~S}$ proteasome is a serine protease, the $\mathrm{Zn}^{2+}$-binding site has been recorded to possess a high affinity; the previously mentioned site of binding and the catalytic mechanism are assumably separate from each other[30]. Reportedly, $\mathrm{Zn}^{2+}$ is responsible for the induction of inhibitory dissociation of the subunits of drosophila proteasome [31]. The majority of carboxyl proteases are not inhibited in large manner by the intensity of interactional cell $\mathrm{Zn}^{2+}$, and metallo-proteases demand $\mathrm{Zn}^{2+}$ for the purpose of activity, and in case a drug can raise the anti-proteolytic impact of endogenous $\mathrm{Zn}^{2+}$ in a safe manner, this might decrease the excessive rates of reaction of some or all Cts comprising viral or parasite proteases inhibition. Biguanide (guanylguanidine) creates complexes with $\mathrm{Zn}^{2+}$ and other metal cations. It has been discovered that specific derivatives of biguanide are interactional inhibitors of $\mathrm{Zn}^{2+}$ of protease reactions in examination of enzyme and a lot of degradation of cellular protein in the bioassay of perfused tissue [32]. Furthermore, it has been assessed that $\mathrm{Zn}^{2+}$ deficiency or dysregulation are causing mammalian inflammation and autoimmunity[33]. An association between dysregulation of (a) $\mathrm{Zn}^{2+}$ in diverse types of cells and compartments, (b) one or more exaggerated activity of CysCts, and (c) increased autoimmune/inflammatory processes appears to be probable. Such a relationship provides several therapeutic intervention points[33].

2) Biguanides: the Cts inhibitory effect of $\mathrm{Zn}^{2+}$ is mediated by interactions with series of compounds known as Biguanides (Fig 1) as Phenformin and Metformin (oral hypoglycemic agent and was used in the 1940s for treatment of Influenza virus[34]) and Cts proteases by formation of " $\mathrm{Zn}^{2+}$ sandwich" in between different derivatives of biguanide and the cysteinyl cathepsins active site regions. Biguanide forms complexes of bidentate $\mathrm{Zn}^{2+}$ via the two imino nitrogens, and also the Cysteinyl Cathepsin possess bidentate affinity for $\mathrm{Zn}^{2+}$ consisting of Cys(thiolate)- His(imidazole) active region [25]. The partners of imino biguanide nitrogens and the thiolate-imidazole catalytic are capable of forming complex of mixed type with $\mathrm{Zn}^{2+}$ which is centrally coordinated in a reversible manner i.e. a "sandwich of drug- $\mathrm{Zn}^{2+}$-protease" and water accessibility to the $\mathrm{Zn}^{2+} 2$ uninhabited sites, and The potency of inhibition is determined by forces of attractiion vs. repulsiveness which stabilize the metal sandwich and the Electrostac Atraction, Hydrogen Bonds, Forces of Van der Waals, Hydrophobic Binding and Pi Interacons of the Biguanide Substituent Moieties and the Cysteinyl Cathepsin Subsites[25, 32]. 
<smiles>N=C(N)NC(=N)N</smiles>

(a)<smiles>CN(C)C(=N)NC(=N)N</smiles>

(b)<smiles>N=C(N)NC(=N)NCCc1ccccc1</smiles>

(c)

Fig. 3 structure of a- biguanide, b- Metformin and c- Phenformin [116]

3) Bromelain and Lactoferrin: Inhibitor of bromelain VI [BI-VI; $5.89 \mathrm{kDa}$; heavy chain $(\mathrm{H}, 41$ residues amino acid) and light chain (L, 11 residues of amino acid) that is a peptide exist in stem of pineapple acts as cathepsin $\mathrm{L}$ inhibitor $\left(\mathrm{Ki} 0.2 \times 10^{-6} \mathrm{M}\right)$ in a selective manner and at limited degree trypsin [35].On contrary, Lactoferrin is a protein exists at a lot of contents of human milk than these of cow's milk. It leads to inhibition of cathepsin L in a strong manner. The lactoferrin IC50 in opposition to cathepsin L was $10^{-7} \mathrm{M}$. Meanwhile, the synthetic peptide IC50 that aims at active site of cathepsin $\mathrm{L}$ was $10^{-5} \mathrm{M}$. Remarkably, lactoferrin has no role in inhibiton of both cathepsin $\mathrm{H}$ and cathepsin B[36]. Consequenty, this might permit cathepsin L fine targeting for impediment of internalization of SARS-CoV-2, meanwhile averting potential endangers to the cells. Both Bromelain and lactoferrin -VI, that manifest high selectiveness to cathepsin L, comprise multiple bonds of disulfide, adjusted in core of protein. As inhibition of cathepsin $\mathrm{L}$ is proceeded by thiol chemistry that provide much more preferentially cathepsin L inhibition instead of other cathepsins [2].

4) Vitamin D: which is produced within skin providing an adequate vitamin $D$ source. Vitamin D subsequent metabolism to its active metabolite $1,25(\mathrm{OH})_{2} \mathrm{D}_{3}$ [37]., qRTPCR affirmed a transcriptomic analysis, revealed that expression of cathepsin L undergoes inhibition by $1,25(\mathrm{OH})_{2} \mathrm{D}_{3}$ in MDA-MB-231 cells of breast cancer [38]. The previously mentioned protease has been associated with malignancy promotion in several types of cancer and viral infections and the inhibition of this protrease via $1,25(\mathrm{OH})_{2} \mathrm{D}_{3}$ could be a part of the antitumor action of $1,25(\mathrm{OH})_{2} \mathrm{D}_{3}$ in cancer of breast[39].

5) Hydroxychloroquine and Chloroquine: Hydroxychloroquine and Chloroquine are aminoquinolines which are commonly prescribed as treatment for rheumatic diseases and malaria, namely rheumatoid arthritis and systemic lupus erythematosus. The increase of endosomal $\mathrm{pH}$ one of the renowned cloroquine actions, that are capable to result in inhibition of activation of CatL, and subsequently protein $\mathrm{S}$ activation in the endosomes would be diminished [40], also Chloroquine interfere with ACE2 receptors glycosylation, an effect that is capable to cause impairment to the attachment of SARSCoV particles to attachment of ACE2 [41-43].

6) Heparin: The spike protein of SARS-CoV-2 has an affinity to bind with heparin and its derivates and, consequently, inhibit viral infection [44]. In addition to that, it was 
discovered that glycosaminoglycans bind to the site of cleavage of spike S1/S2 proteolytic (CatL) [45]. Considering that CatL is fundamental in term of viral invasion[46-49] and representation of heparin as CatL activity inhibitor by enhancing serpin inhibition of the CatL [50], the observed antiviral features for heparin could be associated with $=$ impaired S1/S2 proteolytic throughout the time of SARS-CoV-2 cell invasion [51].

7) Ivermectin: According to the fact which states that proteolytical cleavage of $S$ protein of SARS-CoV-2 virus occurs via type-II transmembrane serine protease (TMPRSS2) into subunits of S1 and S2 [52]. Ivermectin revealed high affinity of binding to the viral S protein and also surface receptors of the human cell ACE-2 and TMPRSS2. It has been found that ivermectin is docked between the ACE2 receptor and viral spike [53]. S protein activation via TMPRSS2 is capable of making activity of cathepsin $\mathrm{L}$ and low $\mathrm{pH}$ level unneeded for the fusion of viral envelope with the endosomal membrane [54]. Ivermectin molecular docking along with TMPRSS2 proposed an essential ivermectin role in terms of inhibition of the virus entry to the host cell, potentially by endosomal $\mathrm{pH}$ increase. In addition to that, it effectively binds to both serine-type protease or main protease (Mpro) and papain-like protease (PLpro) of SARS-CoV-2; thereby, it may also contribute to orevention of the viral polyproteins post-translational processing[55-60].

8) Statins: Legumain (asparaginyl endopeptidase) is defined as cysteine protease which is principally confined to the lysosomes and was characterized for the first time in mammals in 1997 [61], and its over-expression is correlated with instability of atherosclerotic plaque and malignancy of cancer [62, 63].It was found that legumain plays a role in cathepsin B and L maturation process [64]. Lately, it has been reported that legumain mRNA down-regulation in macrophages is ascribed to atorvastatin and also cathepsin L activity decrease in patients who were treated from statin with aortic aneurysms $[65,66]$. In addition to that, it has been reported that extracellular glucose regulate the cysteine proteases cathepsin $\mathrm{B}, \mathrm{D}, \mathrm{L}$ and $\mathrm{S}$ activity in murine macrophagelike J774A.1 cells and human monocytes [67]. This, together along with the findings that simvastatin declined metabolism of glucose in myotubes and the reported legumain mRNA down-regulation by atorvastatin seen in monocytes [66].

9) Dexamethasone: Dexamethasone is responsible for inhibition of cathepsins B and L $[68,69]$ and is capable of being used with patient who develop a severe respiratory disorder and demands support of oxygen as this drug has already been represented to decrease mortality in this specific clinical situation [70]. Oral secretolytic agent Bromhexine hydrochloride is also taken into consideration as a probable candidate to add to such combinations which revealed inhibitory activity in opposition to TMPRSS2 and it is generally safe to use [71]. In addition to that, glycopeptide antibiotic Teicoplanin usage in hospitalized patients who evolve pneumonia as an outcome of secondary infections of bacteria since this antibiotic was represented as an inhibitor of cathepsin L $[72,73]$ and thereby might be advantageous in controlling viral infection as well. 
10) Quercetin: it is defined as cysteine proteinases (cathepsins) from leishmania spp. Are propitious molecular targets in opposition to leishmaniasis. leishmania Mexicana cathepsin 1 is fundamental in the life span of parasite and of a crucial importance in mammals virulence factor. Natural products which were observed to show activity of antileishmanial manner were screened as an integral part of our continuous work which is dedicated to design inhibitors against the L. meexicana cathepsin L-like Rcpb2.8 amid them, tetrahydrorobustaflavone, agathisflavone, 3-oxo-urs-12-en-28oic acid, and quercetin revealed obvious activity of inhibition on Rcpb2.8 along with IC50 values varying from 0.43 to $18.03 \mu \mathrm{M}$. (74). Quercetin is a powerful inhibitor of cathepsin with an IC50 in the low micromolar range [75]. Quercetin is a renowned and easily obtainable supplement and, thereby, it must be taken into consideration as an adjuvant in order to weaken or prevent such viral infections course. An elevated endosomal $\mathrm{pH}$ leads to inhibition of Cathepsin $\mathrm{B} / \mathrm{L}$ activity and, thereby, chloroquine treatment will be capable of working [76]. A clinical trial of quercetin has been conducted on COVID-19 patients.(NCT04468139). There are studies using Quercetin intravenously( along with corn smut) in patients with Covid 19 with positive outcome(117)

11) Melatonin: In term of organism functions, melatonin is capable of stabilization and regulation of plenty of its functions. Recently, it has been shown by investigators that administration of melatonin in low quantity doses did not only led to stimulatory impact on organism immune reactions, but also credit goes to-antioxidant properties, as it perform neutralization to the detrimental impact of stress [77-79]. it retrieves the organism hormonal homeostasis [80,81]. This impact reliesin on the used doses, but first and foremost it relies on the exogenous melatonin administration time [82,83]. this illustration of the melatonin immunological function became the foundation for the implementation of this hormone in the therapeutic approaches of several diseases, first and foremost in immunotherapy of neoplasm [84,85-87]. lysosomal space has a critical contribution in the organism defensive processes, controls of endocrine glands secretion, liquidation and transportation of substances which are foreign and utilized cellular organelles $[88,89]$. It actively plays a role in adaptive organism reactions, and preserves the organism stability in various environmental circumstances. Our outcomes have indicated that melatonin had a significant impact on the investigated glycosidases activity (BGRD, NAG), PROTEOLYTIC ENZYMES (aap,Cath.D and L) and lysosomal acid lipase of the lysosomal compartment. Exogenous melatonin, administered for 7 and 14 days in dose of $20 \mathrm{mg} / \mathrm{kg} \mathrm{b.w} \mathrm{declined} \mathrm{the} \mathrm{activities} \mathrm{of} \mathrm{all} \mathrm{the}$ examined lysosomal space enzymes in the kidney and liver of female and male mice [90].

12) Gallinamide A: Several natural marine products are strong proteases inhibitors, an essential drug target class in human diseases. Thereby, extracts of marine cyanobacteria were evaluated for inhibition role to cathepsin L of human. Here, we have revealed that gallinamide A inhibitis the cysteine protease cathepsin L of human in selective and potent manner [91] 
13) Catfish: It was figured that in majority of the proteinase Cathepsin L cause degradation of myofibril protein in pacific whitening fish surimi [92] and cannot be removed by conventional bleaching [93]. The purification of natural protease inhibitors has been successfully achieved into cystatin from eggs of Glassfish [94], ovarian fluid from tilapia fish, eggs of salmon, skin of fish from cod and Atlantic salmon [95], plasma of chum salmon and as inhibitors of trypsin from eggs of skipjack tuna[96], Catfish (pangasius sp.) in addition to other creatures, represent a source of natural inhibitors and enzymes which are capable of existing within cells (intracellular) and are either outside the cell (extracellular) or attached to the membrane [97]. Inhibitor of cathepsin was obtained by extraction from the muscle of catfish in the phase of pre-rigor. The cathepsin enzyme is found within the lysosomes. Meanwhile the inhibitor is found at pre-rigor phase and in cytoplasm, inhibitor of cathepsin and cathepsin itself continue to be separated [98].

\section{3) Discussion}

The novel coronavirus SARS-CoV-2 has spread globally in 2020 causing the pandemic atypical pneumonia coronavirus disease with more than 128 million confirmed cases and more than 2 million deaths worldwide (WHO statistics 31 march 2021). Pharmacological investigation of SARS-CoV-2 infection considers the endocytic pathways through which the opportunistic virus take advantage of the host cell and enters in the human lung epithelium. This fusion process is the most important moment for the virus to start the synthesis of viral proteins and the replication mechanism. Recent studies conducted some insight into the cell biology of the SARS-CoV-2 human virus showing that some receptors found on host cells' membrane are substantial for SARS-CoV-2 fusion and endocytosis, including ACE2 (Angiotensin Converting Enzyme 2), TMPRSS2 (Transmembrane Serine Protease 2) and cathepsin L. ACE2 receptors have many biological roles, however, it has been linked with COVID-19 through its binding with the spike protein of SARS-CoV-2, which allow the virus to exposed to TMPRSS2 and cathepsin L enzymatic receptors, thus enhance the fusion and endocytosis process.

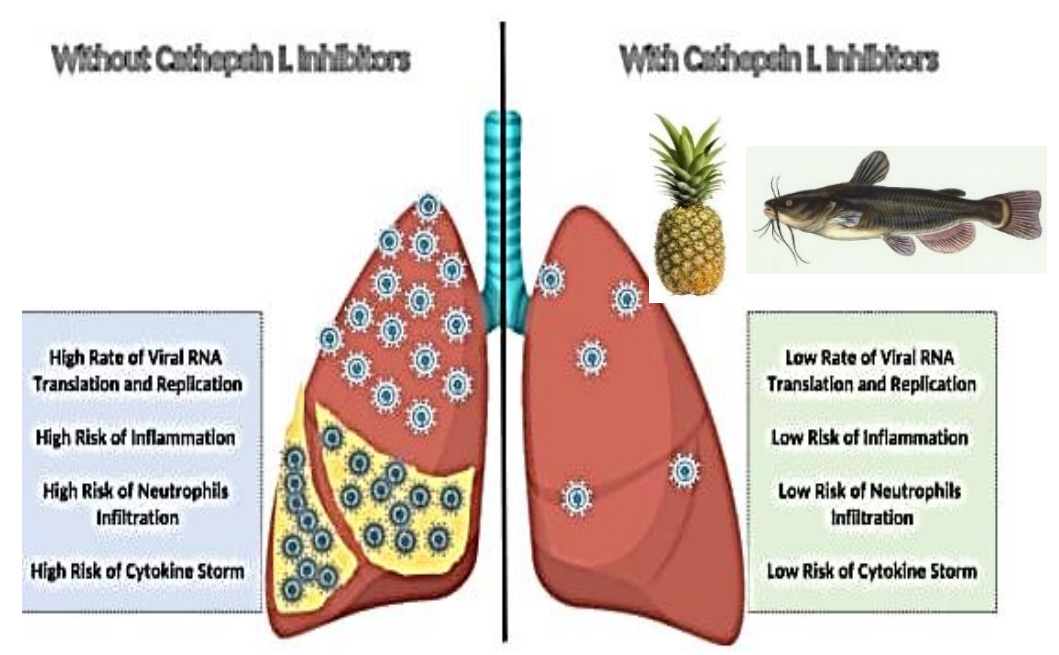

Fig. 4 
Cathepsin L, a cysteine protease, tends to increase in chronic inflammation. It is expressed in all tissues and cells. It is responsible of proteolysis of protein antigens derived by pathogen endocytosis. Cysteine cathepsin inhibitors counteract the inflammatory response in combination with autoimmunity. Several studies demonstrates that multiple caspases inhibition are mediated by $\mathrm{Zn}^{2+}$-binding allosteric exosites. It has been found that $\mathrm{Zn}^{2+}$ deficiency or dysregulation leads to an exaggerated activity of CysCts and increased autoimmune/inflammatory processes. $\mathrm{Zn}^{2+}$ metal can be safely combined with a drug that increases the anti-proteolytic effect of endogenous $\mathrm{Zn}^{2+}$ lowering the excessive activity of some CysCts. Biguanide derivatives complex with $\mathrm{Zn}^{2+}$ have been found to be promising inhibitors of CysCts protease reactions.

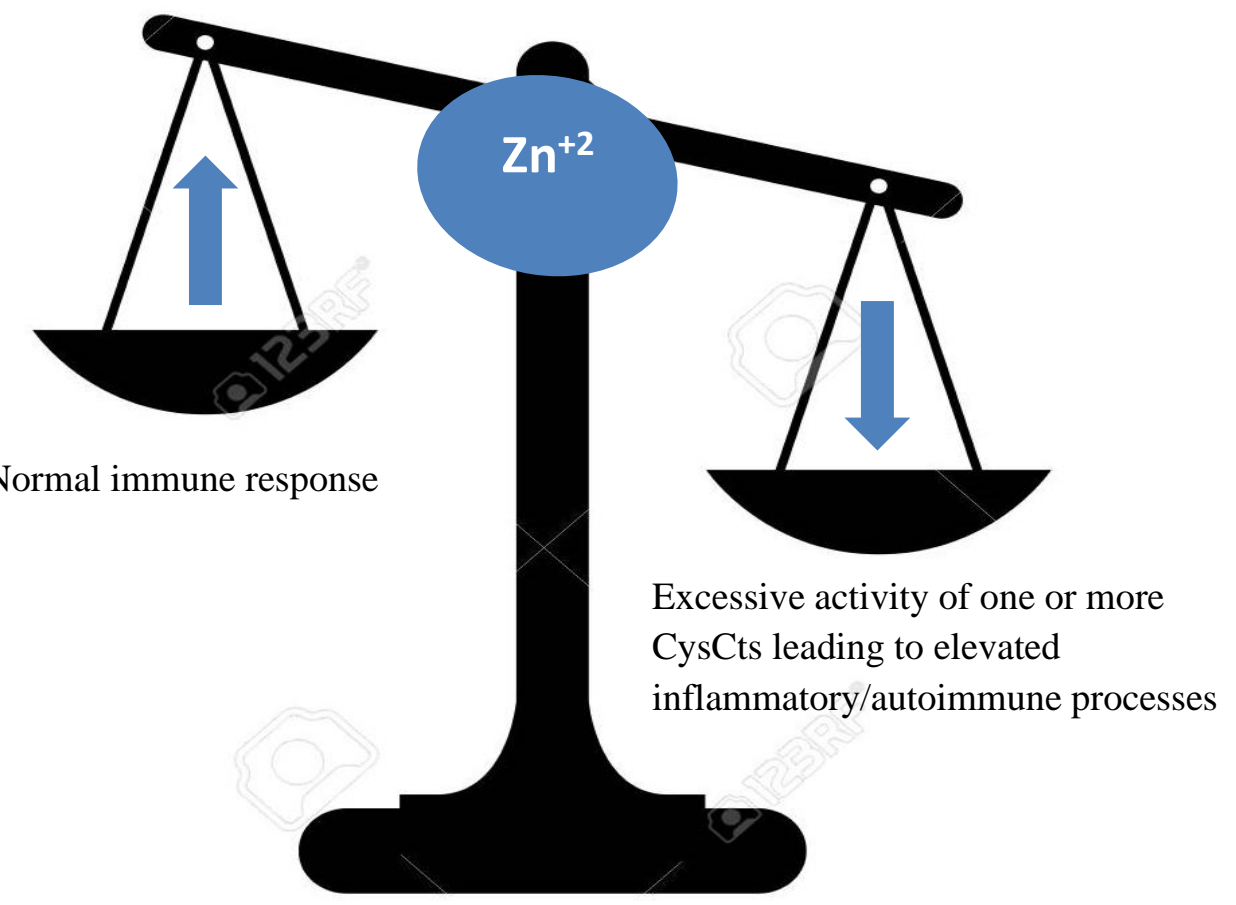

Fig. 5 : The effect of zinc on immune response

Although some drugs

available nowadays have anti-cathepsin L activity like heparin, chloroquine, hydroxychloroquine, teicoplanin and amantadine, these drugs may exert anti-viral effect only when given at high doses (supra-therapeutic doses). Therefore, it is better to find or design a drug with higher potency and more selective against cathepsin L enzyme to ensure its efficiency and safety and when treating COVID-19 patients.

Another issue is the anticipated efficacy after inhibition of cathepsin L protease. As known, SARS-CoV-2 have more than one pathway to enter and infect human cells, 
either via serine protease (TMPRSS2) or cysteine protease (cathepsin L). Blocking cathepsin L only will not probably be effective in reducing the viral RNA introduction to the host cells, in addition to its translation and replication process. This issue is the expected cause of unsuccessful treatment with some cathepsin L inhibitors (e.g. hydoxychloroquine) in vivo, despite its successfulness in eliminating SARS-CoV-2 in vitro. In this context, inhibition of both serine and cysteine proteases could result in more powerful efficacy in treating and protecting against COVID-19. Covid-19 requires the infection of pulmonary epithelial cells by cathepsin L (102) with upregulation of cathepsin L production via IL-6 (103).

\section{4) Molecular Docking studies:}

Metformin (Biguanide) through its two imino nitrogens forms a bidentate $\mathbf{Z n}^{\mathbf{+ 2}}$ complex with the three amino acids Cysteine-25 (thiolate), Histidine-163

(imidazole) and Aspartate-162 present at the active binding site of the Cathepsin L (Drug-Zn ${ }^{+2}$-protease sandwich). Metformin- $\mathrm{Zn}^{+2}$ complex has the exact binding mode and interactions as the co-crystallized $\mathrm{Zn}^{+2}$ (PDB ID 4axI) because it forms the same two H-bonding with Cys-25 and His-163 as the cocrystallized ligand but with an additional H-bond with Asp-163.

The Cathepsin L protein was prepared by Autodock tool program and docking studies were performed using Pyrx and then visualized by Pymol.

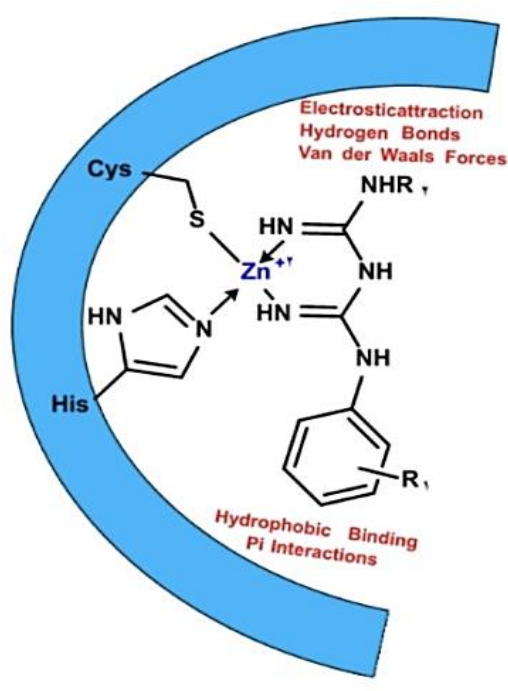

Biguanide zinc complexes in cysteinyl cathepsin active site region

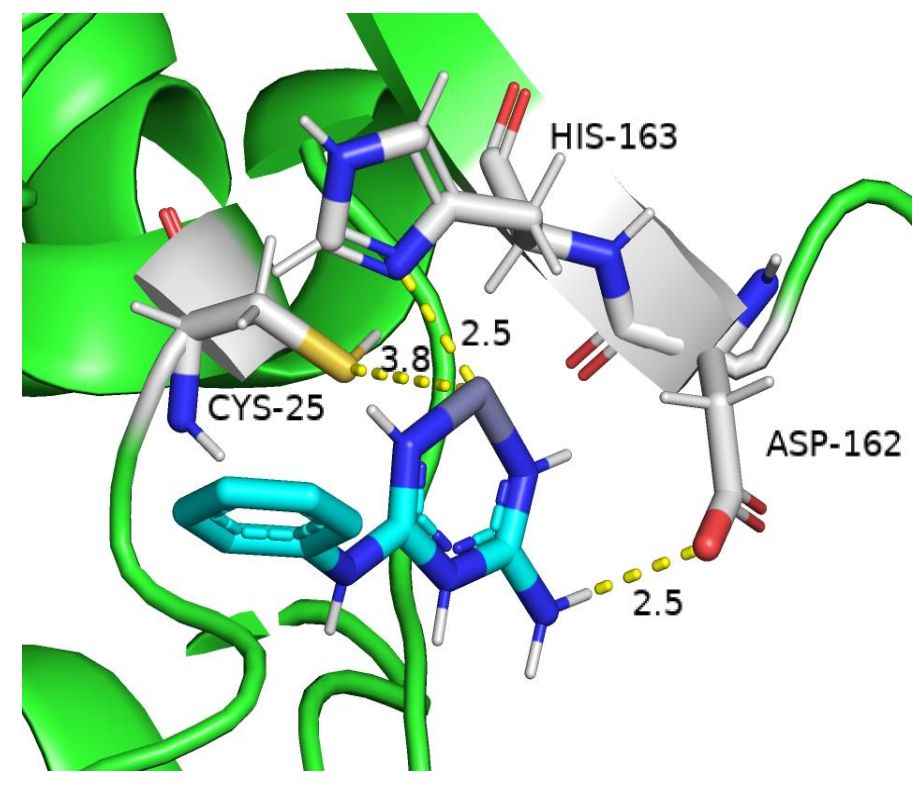

Fig. 7 Molecular docking of Cathepsin L Inhibited by Metformin$\mathrm{Zn}^{+2}$ complex.
Fig. 6 Biguanide zinc complexes in cysteinyl cathepsin active site region 


\section{References}

1. Rudzińska, M., et al., The Role of Cysteine Cathepsins in Cancer Progression and Drug Resistance. 2019. 20(14): p. 3602.

2. Madadlou, A.J.E.J.o.P., Food proteins are a potential resource for mining cathepsin L inhibitory drugs to combat SARS-CoV-2. 202 :885 .0p. 173499.

3. Pu, J., et al., Mechanisms and functions of lysosome positioning. J Cell Sci, 2016. 129(23): p. 4329-4339.

4. Fonović, M. and B. Turk, Cysteine cathepsins and extracellular matrix degradation. Biochim Biophys Acta, 2014. 1840(8): p.70-2560 .

5. Kukor, Z., et al., Presence of cathepsin B in the human pancreatic secretory pathway and its role in trypsinogen activation during hereditary pancreatitis. $\mathrm{J}$ Biol Chem, 2002. 277(24): p. 21389-96.

6. Reiser, J., B. Adair, and T. Reinheckel, Specialized roles for cysteine cathepsins in health and disease. J Clin Invest, 2010. 120(10): p. 3421-31.

7. Gocheva, V. and J.A. Joyce, Cysteine cathepsins and the cutting edge of cancer invasion. Cell Cycle, 2007. 6(1): p. 60-4.

8. Sudhan, D.R. and D.W .Siemann, Cathepsin L inhibition by the small molecule KGP94 suppresses tumor microenvironment enhanced metastasis associated cell functions of prostate and breast cancer cells. Clin Exp Metastasis, 2013. 30(7): p. 891-902.

9. Chen, S., et al., Cathepsins in digestive cancers. Oncotarget, 2017. 8(25): p. 41690-41700.

10. Turk, V., B. Turk, and D. Turk, Lysosomal cysteine proteases: facts and opportunities. Embo j, 2001. 20(17): p. 4629-33.

11. Brömme, D. and S. Wilson, Role of cysteine cathepsins in extracellular proteolysis, in Extracellular matrix degradation. 2011, Springer. p. 23-51.

12. Turk, B., D. Turk, and G.S.J.C.p.d. Salvesen, Regulating cysteine protease activity: essential role of protease inhibitors as guardians and regulators. 2002. 8(18): p.1637-1623 .

13. Verma, S., R. Dixit, and K.C. Pandey, Cysteine Proteases: Modes of Activation and Future Prospects as Pharmacological Targets. 2016. 7(107.(

14. Hämälistö, S. and M. Jäättelä, Lysosomes in cancer-living on the edge (of the cell). Current Opinion in Cell Biology, 2016. 39: p. 69-76. 
15. Sui, H., et al., Overexpression of Cathepsin L is associated with chemoresistance and invasion of epithelial ovarian cancer. Oncotarget, 2016. 7(29): p. 45995-46001.

16. Zheng, X., et al., Senescence-initiated reversal of drug resistance: specific role of cathepsin L. Cancer Res, 2004. 64(5): p. 1773-80.

17. Han, M.L., et al., Cathepsin L upregulation-induced EMT phenotype is associated with the acquisition of cisplatin or paclitaxel resistance in A549 cells .Acta Pharmacol Sin, 2016. 37(12): p. 1606-1622.

18. Zheng, X., et al., Cathepsin L inhibition suppresses drug resistance in vitro and in vivo: a putative mechanism. Am J Physiol Cell Physiol, 2009. 296(1): p. C65-74.

19. Lindner, H.A., et al., The papain-like protease from the severe acute respiratory syndrome coronavirus is a deubiquitinating enzyme. 2005. 79(24): p. $15199-15208$.

20. Schornberg, K., et al., Role of endosomal cathepsins in entry mediated by the Ebola virus glycoprotein. 2006. 80(8): p.4178-4174 .

21. Ou, X., et al., Characterization of spike glycoprotein of SARS-CoV-2 on virus entry and its immune cross-reactivity with SARS-CoV. 2020. 11(1): p. 1-12.

22. Buzon, M.J., et al., Inhibition of HIV-1 integration in ex vivo-infected CD4 T cells from elite controllers. Journal of virology, 2011. 85(18): p. 9646-9650.

23. Guicciardi, M.E., et al., Cathepsin B knockout mice are resistant to tumor necrosis factor- $\alpha$-mediated hepatocyte apoptosis and liver injury: implications for therapeutic applications. 2001. 159(6): p. 2045-2054.

24. Hsing, L.C., et al., Roles for cathepsins S, L, and B in insulitis and diabetes in the NOD mouse. 2010. 34(2): p. 96-104.

25. Lockwood, T.D.J.B., Biguanide is a modifiable pharmacophore for recruitment of endogenous $\mathrm{Zn} 2+$ to inhibit cysteinyl cathepsins: review and implications. 2019. 32(4): p. 575-593.

26. Perry, D.K., et al., Zinc is a potent inhibitor of the apoptotic protease, caspase3: a novel target for zinc in the inhibition of apoptosis. 1997. 272(30): $\mathrm{p}$. $1.18533-8530$

27. Eron, S.J., et al., Multiple mechanisms of zinc-mediated inhibition for the apoptotic caspases-3,-6,-7, and-8. 2018. 13(5): p. 1279-1290.

28. Parvez, M.K. and A.A.J.V.r. Khan, Molecular modeling and analysis of hepatitis E virus (HEV) papain-like cysteine protease. 2014. 179: p. 220-224. 
29. Nakajima, E., et al., Activation of the mitochondrial caspase pathway and subsequent calpain activation in monkey RPE cells cultured under zinc depletion. 2014. 28(1): p. 85-92.

30. Chouduri, A.U., et al., High affinity $\mathrm{Zn} 2+$ inhibitory site (s) for the trypsinlike peptidase of the 20S proteasome. 2008. 477(1): p. 113-120.

31. Kiss, P., et al., Zn2+-induced reversible dissociation of subunit Rpn10/p54 of the Drosophila 26 S proteasome. The Biochemical journal, 2005. 391(Pt 2): p. 301-310.

32. Sweeney, D., M.L. Raymer, and T.D.J.B.p. Lockwood, Antidiabetic and antimalarial biguanide drugs are metal-interactive antiproteolytic agents. 2003. 66(4): p. 663-677.

33. Bonaventura, P., et al., Zinc and its role in immunity and inflammation. 2015. 14(4): p. 277-285.

34. Bailey, C.J.J.D., Metformin: historical overview. 2017. 60(9): p. 1566-1576.

35. Pavan, R., S. Jain, and A. Kumar, Properties and therapeutic application of bromelain: a review. Biotechnology research international, 2012. 2012.

36. Sano, E., et al., Cysteine protease inhibitors in various milk preparations and its importance as a food. Food research international, 2005. 38(4): p. 427-433.

37. Bikle, D., Nonclassic Actions of Vitamin D. The Journal of Clinical Endocrinology \& Metabolism, 2009. 94(1): p. 26-34.

38. Swami, S., et al., Vitamin D growth inhibition of breast cancer cells: gene expression patterns assessed by cDNA microarray. Breast cancer research and treatment, 2003. 80(1): p. 49-62.

39. Álvarez-Díaz, S., et al., Vitamin D: Proteases, protease inhibitors and cancer. Cell Cycle, 2010. 9(1): p. 32-37.

40. Gonzalez-Suarez, I., et al., A new pathway that regulates 53BP1 stability implicates cathepsin L and vitamin D in DNA repair. The EMBO journal, 2011. 30(16): p. 3383-3396.

41. Vincent, M.J., et al., Chloroquine is a potent inhibitor of SARS coronavirus infection and spread. Virology journal, 2005. 2(1): p. 1-10.

42. De Wilde, A.H., et al., Screening of an FDA-approved compound library identifies four small-molecule inhibitors of Middle East respiratory syndrome coronavirus replication in cell culture. Antimicrobial agents and chemotherapy, 2014. 58(8): p. 4875-4884. 
43. Keyaerts, E., et al., In vitro inhibition of severe acute respiratory syndrome coronavirus by chloroquine. Biochemical and biophysical research communications, 2004. 323(1): p. 264-268.

44. Mycroft-West, C., et al., Heparin inhibits cellular invasion by SARS-CoV-2: structural dependence of the interaction of the surface protein (spike) S1 receptor binding domain with heparin. BioRxiv, 2020.

45. Kim, S.Y., et al., Glycosaminoglycan binding motif at S1/S2 proteolytic cleavage site on spike glycoprotein may facilitate novel coronavirus (SARSCoV-2) host cell entry. BioRxiv, 2020.

46. Huang, I.-C., et al., SARS coronavirus, but not human coronavirus NL63, utilizes cathepsin L to infect ACE2-expressing cells. Journal of Biological Chemistry, 2006. 281(6): p. 3198-3203.

47. Simmons, G., et al., Inhibitors of cathepsin L prevent severe acute respiratory syndrome coronavirus entry. Proceedings of the National Academy of Sciences, 2005. 102(33): p. 11876-11881.

48. Simmons, G., et al., Characterization of severe acute respiratory syndromeassociated coronavirus (SARS-CoV) spike glycoprotein-mediated viral entry. Proceedings of the National Academy of Sciences, 2004. 101(12): p. 42404245.

49. Wang, D., et al., Clinical characteristics of 138 hospitalized patients with 2019 novel coronavirus-infected pneumonia in Wuhan, China. Jama, 2020. 323(11): p. 1061-1069.

50. Higgins, W.J., et al., Heparin enhances serpin inhibition of the cysteine protease cathepsin L. Journal of Biological Chemistry, 2010. 285(6): p. 37223729.

51. Gomes, C.P., et al., Cathepsin L in COVID-19: from pharmacological evidences to genetics. Frontiers in cellular and infection microbiology, 2020. 10.

52. Hoffmann, M., et al., SARS-CoV-2 cell entry depends on ACE2 and TMPRSS 2 and is blocked by a clinically proven protease inhibitor. cell, 2020. 181(2): p. $271.280-\mathrm{e} 8$.

53. Lehrer, S. and P.H. Rheinstein, Ivermectin docks to the SARS-CoV-2 spike receptor-binding domain attached to ACE2. in vivo, 2020. 34(5): p. 30233026.

54. Glowacka, I., et al., Evidence that TMPRSS2 activates the severe acute respiratory syndrome coronavirus spike protein for membrane fusion and reduces viral control by the humoral immune response. Journal of virology, 2011. 85(9): p. 4122-4134. 
55. Caly, L., et al., The FDA-approved drug ivermectin inhibits the replication of SARS-CoV-2 in vitro. Antiviral research, 2020. 178: p. 104787.

56. Rowland, R.R., et al., Intracellular localization of the severe acute respiratory syndrome coronavirus nucleocapsid protein: absence of nucleolar accumulation during infection and after expression as a recombinant protein in vero cells. Journal of virology, 2005. 79(17): p. 11507-11512.

57. Tay, M., et al., Nuclear localization of dengue virus (DENV) 1-4 nonstructural protein 5; protection against all 4 DENV serotypes by the inhibitor Ivermectin. Antiviral research, 2013. 99(3): p. 301-306.

58. Timani, K.A., et al., Nuclear/nucleolar localization properties of C-terminal nucleocapsid protein of SARS coronavirus. Virus research, 2005. 114(1-2): p. 23-34.

59. Wagstaff, K.M., et al., Ivermectin is a specific inhibitor of importin $\alpha / \beta$ mediated nuclear import able to inhibit replication of HIV-1 and dengue virus. Biochemical Journal, 2012. 443(3): p. 851-856.

60. Yang, S.N., et al., The broad spectrum antiviral ivermectin targets the host nuclear transport importin $\alpha / \beta 1$ heterodimer. Antiviral research, 2020. 177: $\mathrm{p}$. 104760 .

61. Chen, J.-M., et al., Cloning, isolation, and characterization of mammalian legumain, an asparaginyl endopeptidase. Journal of Biological Chemistry, 1997. 272(12): p. 8090-8098.

62. Liu, C., et al., Overexpression of legumain in tumors is significant for invasion/metastasis and a candidate enzymatic target for prodrug therapy. Cancer research, 2003. 63(11): p. 2957-2964.

63. Papaspyridonos, M., et al., Novel candidate genes in unstable areas of human atherosclerotic plaques. Arteriosclerosis, thrombosis, and vascular biology, 2006. 26(8): p. 1837-1844.

64. Shirahama-Noda, K., et al., Biosynthetic processing of cathepsins and lysosomal degradation are abolished in asparaginyl endopeptidase-deficient mice. Journal of Biological Chemistry, 2003. 278(35): p. 33194-33199.

65. Abisi, S., et al., Effect of statins on proteolytic activity in the wall of abdominal aortic aneurysms. British journal of surgery, 2008. 95(3): p. 333337.

66. Wang ,Z.h., et al., Pleiotropic effects of atorvastatin on monocytes in atherosclerotic patients. The Journal of Clinical Pharmacology, 2010. 50(3): p. 311-319.

67. Moheimani, F., et al., Inhibition of lysosomal function in macrophages incubated with elevated glucose concentrations: a potential contributory factor 
in diabetes-associated atherosclerosis. Atherosclerosis, 2012. 223(1): p. 144151.

68. Crossland, H., et al., Low-dose dexamethasone prevents endotoxaemiainduced muscle protein loss and impairment of carbohydrate oxidation in rat skeletal muscle. The Journal of physiology, 2010. 588(8): p. 1333-1347.

69. Nguyen-Ba, G., et al., Modulatory effect of dexamethasone on ornithine decarboxylase activity and gene Expression: a possible post-transcriptional regulation by a neutral metalloprotease. Cell Biochemistry and Function: Cellular biochemistry and its modulation by active agents or disease, 1994. 12(2): p. 121-128.

70. Group, R.C., Dexamethasone in hospitalized patients with Covid-19preliminary report .New England Journal of Medicine, 2020.

71. Lucas, J.M., et al., The androgen-regulated protease TMPRSS2 activates a proteolytic cascade involving components of the tumor microenvironment and promotes prostate cancer metastasis. Cancer discovery, 2014. 4 :(11)p. 13101325 .

72. Zhang, J., et al., Teicoplanin potently blocks the cell entry of 2019-nCoV. BioRxiv, 2020.

73. Zhou, N., et al., Glycopeptide antibiotics potently inhibit cathepsin 1 in the late endosome/lysosome and block the entry of ebola virus ,middle east respiratory syndrome coronavirus (MERS-CoV), and severe acute respiratory syndrome coronavirus (SARS-CoV). Journal of Biological Chemistry, 2016. 291(17): p. 9218-9232.

74. de Sousa LR, Wu H, Nebo L, Fernandes JB, da Silva MF, Kiefer W, Schirmeister T, Vieira PC. Natural products as inhibitors of recombinant cathepsin L of Leishmania mexicana. Exp Parasitol. 2015 Sep;156:42-8. doi: 10.1016/j.exppara.2015.05.016. Epub 2015 Jun 1. PMID: 26044356.

75. Frlan R, Gobec S (2006) Inhibitors of cathepsin B. Curr Med Chem 13:23092327. https ://doi.org/10.2174/09298 6706777935122

76. Schrezenmeier E, Dorner T (2020) Mechanisms of action of hydroxychloroquine and chloroquine: implications for rheumatology.

77. Nat Rev Rheumatol 16(3):155-166. https ://doi.org/10.1038/s4158 4-0200372-x(Epub 2020/02/09).

78. King M, Scaiano JC. The excited states of melatonin. J Photochem Photobiol 1997; 65:538-542.

79. Liebmann PM, Wolfer A, Felsner P, Hofer D, Schauenstein K. 
80. Melatonin and immune sy stem. Int Arch Allergy Immunol

81. 1997; 112:203-211.

82. Stasica P, Ulanski P, Rosiak JM. Melatonin as a hydroxyl radical scavenger. J Pineal Res 1998; 25:65-66.

83. Sainz RM, Mayo JC, Reiter RJ, Antolin I, Esteban MM, Rodriquez C. Melatonin regulates glucocorticoid receptor: an

84. answer to its antiapoptotic action in thymus. Faseb J 1999;

85. 13:1547-1557.

86. Zeman M, Buyse J, Lamosova D, Herichova I, Decuypere E. Role of melatonin in the control of growth and growth hormone

87. secretion in poultry. Domest Anim Endocrinol 1999;

88. 17:199-209.

89. Lissoni P, Barni S, Tancini G, Mainini E, Piglia F, Maestroni GJM, Lewinski A. Immunoendocrine therapy with low-dose subcutaneous interleukin-2 plus melatonin of locally advanced or metastatic endocrine tumors. Oncology 1995; 52:163-166.

90. Luboshitzky R, Shenorr Z, Shochat T, Herer P, Lavie P. Melatonin administered in the afternoon decreases next-day

91. luteinizing hormone levels in men. Lack of antagonism by fl umazenil.

92. J Mol Neurosci 1999; 12:69-75.

93. Maestroni GJM. The immunoneuroendocrine role of melatonin.

94. J Pineal Res 1993; 14:1-10.

95. Caroleo M, Frasca D, Nistico G, Doria G. Melatonin as immunomodulator in immuno-defi cient mice. Immunopharmacol

96. 1992; 23:81-89.

97. Lissoni P, Barni S, Crispino S, Tancini G, Fraschini F. Endocrine and immune effects of melatonin therapy in metastatic cancer

98. patients. Eur J Cancer Clin Oncol 1989; 25:789-795.

99. Maestroni GJM, Conti A, Covacci V. Melatonin-induced immunoopioids: fundamentals and clinical perspectives. Adv Pineal

100. Res 1994; 7:73-81.

101. Van Dyke RW, Ervin LL, Lewis MR, Wang X. Effect of cholera toxin on rat liver lysosome acidifi cation. Biochem Biophys Res

102. Commun 2000; 3:717-721.

103. Zatta P, Taylor A, Zambenedetti P, Milacic R, dell Antone P. Aluminium inhibits the lysosomal proton pump from rat liver.

104. Life Sci 2000; 23:2261-2266. 
105. Witek, B., Ochwanowska, E., Kolataj, A., Slewa, A. \& Stanislawska, I. Effect of melatonin administration on activities of some lysosomal enzymes in the mouse. Neuroendocrinol. Lett. 22, 181-185 (2001).

106. Miller B, Friedman AJ, Choi H, et al. The marine cyanobacterial metabolite gallinamide $\mathrm{A}$ is a potent and selective inhibitor of human cathepsin L. J Nat Prod. 2014;77(1):92-99. doi:10.1021/np400727r.

107. Morrissey, M.T., Hartley, P.S. and An, H. 1995. Proteolysis in pacific whiting and effect of surimi processing. Journal of Aquatic Food Product Technology 4(4):5- 18.

108. Hu, Y., Morioka, K. and Itoh, Y. 2007. Existence of cathepsin L and its characterization in Red Bulleye Surimi. Pakistan Journal of Biological Science 10(1): 78-83.

109. Ustadi, Kim, K.Y. and Kim, S.M. 2005. Purification and identification of a protease inhibitor from glassfish (Liparis tanakai) Eggs. Journal of Agricultural and Food Chemistry, 53:7667-7672.

110. Olonen, A. 2004. High molecular weight cysteine proteinase inhibitors in Atlantic Salmon and other fish species. Helsinki, Finland. University of Helsinki, Ph.D dissertation.

111. Li, D.K., Lin, H. and Kim, S.M. 2008. Purification and characterization of a cysteine protease inhibitor from chum salmon (Oncorhynchus keta) Plasma. Journal of Agricultural and Food Chemistry 56:106-111.

112. Choi, J.H., Park, P.J. and Kim, S.K. 2002. Purification and characterization of a trypsin inhibitor from the egg of skipjack tuna Katsuwonus pelamis. Fisheries Science 68:1367-1373.

113. Sentandreu, M.A., Coulis, G. and Ouali, A. 2002. Role of muscle endopeptidases and their inhibitors in meat tenderness. Trends in Food Science and Technology 13(12): 400-421.

114. Huang IC, Bosch BJ, Li F, et al . SARS coronavirus, but not human coronavirus NL63, utilizes cathepsin L to infect ACE2-expressing cells. J Biol Chem. 2006; 281: 3198-203

115. Gerber A, Welte T, Ansorge S, Buhling F, Expression of cathepsin B and $\mathrm{L}$ in human lung epithelial cells is regulated by cytokines, Adv Exp Med Biol. 2000;477:287-92

116. Lockwood T. Biguanide is a modifiable pharmacophore for recruitment of endogenous $\mathrm{Zn} 2+$ to inhibit cysteinyl cathepsins: review and implications. BioMetals. 2019;32(4):575-593. doi:10.1007/s10534-019-001971

117. Nezami, M. and Yamamoto, V. (2020) Biological Disruptive Therapies as Counter Measures for Unpredictable Biological Insults, a Case for Successful Treatment of COVID-19. Advances in Infectious Diseases, 10, 175-183. doi: 10.4236/aid.2020.103018. 